\title{
A subjetividade e a objetividade em Michel Foucault e Karl Marx: Algumas considerações
}

\author{
The subjectivity and objectivity in Michel Foucault and Karl Marx: Some considerations
}

\author{
CDouglas Rossi Ramos ${ }^{[0]}$, Hélio Rebello Cardoso Júnior ${ }^{[b]}$
}

\footnotetext{
${ }^{\text {[a] }}$ Mestrando em Psicologia pela Universidade Estadual Paulista (Unesp), Assis, SP - Brasil, e-mail: dogretes@yahoo.com.br

${ }^{[b]}$ Doutor em Filosofia pela Universidade Estadual de Campinas (Unicamp), professor livre-docente de Filosofia da Universidade Estadual Paulista (Unesp), Assis, SP - Brasil, e-mail: herebell@hotmail.com
}

Recebido: $14 / 10 / 2011$ Received: 10/14/2011

Aprovado: $17 / 04 / 2012$ Approved: 04/17/2012

\section{Resumo}

A questão a respeito da relação entre sujeito e objeto tem sido debatida e explorada nas mais diversas tendências teórico-metodológicas, apresentando ressonâncias e discordâncias referentes às possibilidades de desenvolvimento de uma ciência ou de um sistema filosófico que permitam a construção de um conhecimento sobre o mundo. Dentre tais tendências, as de dois autores, em específico, se diferenciam, respectivamente, em sua complexidade taxionômica e ontológica: Michel Foucault e Karl Marx. 0 objetivo deste texto é discutir aspectos da díade objetividade/subjetividade nos trabalhos desses dois pensadores, apontando algumas correlações entre elas. Para tanto, foi realizada uma discussão a respeito da concepção de conhecimento adotada pelo filósofo francês Michel Foucault e da dificuldade encontrada por seus estudiosos e pensadores em classificar sua obra dentro de alguma tendência ou sistema teórico moderno, além de se discutir a respeito da diferença marcada pelo arcabouço teórico de Marx em relação a outros programas de pesquisa em ciências humanas modernas por não apresentar o indivíduo como entidade ontológica fundamental. A obra de Foucault traz algumas contribuições que, de certa maneira, influenciaram correntes neomarxistas em seu trabalho de reconstituição teórica e de resgate do marxismo.

Palavras-chave: Michel Foucault. Karl Marx. Conhecimento. Subjetividade. Objetividade.

\begin{abstract}
The question of the relationship between subject and object has been discussed and explored in several theoretical and methodological systems, showing resonances and disagreements about the possibilities of developing a science or a philosophical system to allow the construction of the knowledge about the world. Among these, the systems of two authors in particular are different, respectively, regarding the complexity and ontological taxonomic: Michel Foucault and Karl Marx. This work aims to discuss the objectivity and subjectivity in the work of these two thinkers, indicating some possible correlations. The discussions were about the concept of knowledge in Michel Foucault, difficulties experienced by its researchers to classify their work within a classical theoretical system and the difference of Marxist theory in relation to other research programs for
\end{abstract}


not presenting the individual as the fundamental ontological entity. Foucault's work influenced the process of restoration and redemption of Marxism by Marxists groups

Keywords: Michel Foucault. Karl Marx. Knowledge. Subjectivity. Objectivity.

\section{Introdução}

A relação entre sujeito e objeto segue como um desafio à superação ou compreensão dos indivíduos em sua existência no mundo. Esse problema, pertinente não só ao pensamento filosófico, mas também a toda racionalidade científica, vem a ser explicado e compreendido a partir das mais diversas abordagens teóricas, tais como o idealismo platônico na Grécia Antiga, o idealismo clássico de Kant, Hegel e Schopenhauer a partir do século XVIII, as correntes empiristas e positivistas de Bacon, Comte, Locke e Hume no século XIX e, por fim, no decorrer do século XX, a fenomenologia de Husserl, o neopositivismo do círculo de Viena, a psicanálise a partir de Freud e o estruturalismo de expoentes tais como Saussure, Lévi-Strauss, Piaget, Althusser e Lacan. Além dessas referidas abordagens, a de outros dois autores, em específico, se diferenciam, respectivamente, em sua complexidade taxionômica e ontológica: Michel Foucault e Karl Marx.

0 objetivo deste texto é discutir aspectos da díade objetividade/subjetividade nos trabalhos desses dois pensadores, apontando algumas correlações entre elas. A partir disso, pretende-se discutir a concepção de conhecimento adotada pelo filósofo francês Michel Foucault, abordando a respeito de suas ressonâncias com o pensamento de Nietzsche e da dificuldade encontrada por seus estudiosos e pensadores em classificar sua obra dentro de alguma tendência ou sistema teórico moderno. Ainda, será discutido a respeito da diferença marcada pelo arcabouço teórico de Marx em relação a outros programas de pesquisa em ciências humanas modernas, por não apresentar o indivíduo como entidade ontológica fundamental. Por fim, serão apontadas contribuições da obra de Foucault que, de certa maneira, influenciaram algumas correntes neomarxistas em seu trabalho de reconstituição teórica e de resgate do marxismo.

\section{0 conhecimento para Michel Foucault}

Dentre os intelectuais contemporâneos, Foucault talvez seja o mais difícil de definir, pois a complexidade de sua obra, composta por posições e elementos estratégicos, dificulta sua classificação dentro das tradicionais tendências teórico-metodológicas. Dreyfus e Rabinow (1995) em Michel Foucault: uma trajetória filosófica: para além do estruturalismo e da hermenêutica; Rouanet (1987) em As razões do iluminismo; e Merquior (1985) em Michel Foucault ou o niilismo de cátedra trazem uma discussão a respeito dessa dificuldade encontrada entre os estudiosos em situar o pensamento e a obra de Foucault.

Merquior (1985) faz uma crítica a Foucault, na qual o aponta como seguidor da corrente estruturalista. No livro As palavras e as coisas (Foucault, 2002), Foucault teria proclamado a morte do homem, o que o afastaria de uma preocupação tradicional da ideia de sujeito-fundamento e de idealistas, tais como Descartes, Kant e Hegel, ao mesmo tempo em que o aproximaria do estruturalismo. Já para Dreyfus e Rabinow (1995) — apesar de em sua fase denominada de arqueologia Foucault afirmar que "o discurso é um sistema governado por regras" (p. XX), concepção similar aos modelos estruturalistas, e que "o discurso é autônomo e autorreferente" (Dreyfus \& Rabinow, 1995, p. XXI), conforme pregam concepções pós-estruturalistas -, estritamente falando Foucault não seria estruturalista e nem pós-estruturalista, já que mais tarde recuará em relação a essas afirmações e se desviará da tentativa de desenvolver uma teoria geral das regras que governam os sistemas de práticas discursivas, tomando então a genealogia de Nietzsche como ponto de partida para o desenvolvimento de um método que lhe permita tematizar a relação entre verdade, teoria, valores, instituições e práticas sociais. A genealogia passaria a englobar sua arqueologia, configurando-se em um novo método que possibilitaria recursos para explorar essas relações entre poder, saber e corpo. 0 corpo é o objeto de cada tecnologia de poder, que produz seus respectivos enunciados e visibilidades de acordo com as épocas históricas.

Com o abandono da arqueologia como projeto teórico, Foucault não somente se distanciará do estruturalismo, mas também situará “o projeto 
estruturalista historicamente, em um contexto de crescentes práticas isoladoras, ordenadas e sistematizadoras consequências do que chamou tecnologia disciplinar" (Dreyfus \& Rabinow, 1995, p. XXIII).

Para Dreyfus e Rabinow (1995), antes ainda da adoção na arqueologia de técnicas estruturalistas, Foucault se identificara claramente com a tradição da ontologia hermenêutica de Heidegger. Entretanto, Foucault também abandonará suas preocupações quanto à posição hermenêutica e transferirá seu interesse aos efeitos sociais em detrimento de um sentido explícito das práticas cotidianas. A obra de Nietzsche ajuda Foucault a se alertar quanto às necessidades e perigos da abordagem interpretativa. Dessa forma, a genealogia de Nietzsche em relação a Foucault,

[...] da maneira como o poder usa a ilusão do sentido para se favorecer, dá a ele boas razões para ser crítico da hermenêutica, tanto em sua forma de um comentário da vida cotidiana, quanto na sua forma correlata de exegese profunda do que as práticas cotidianas encobrem (Dreyfus \& Rabinow, 1995, p. XXIII).

Por fim, o novo método utilizado por Foucault possibilitaria demonstrar como em nossa cultura os indivíduos se tornariam uma espécie de objeto e de sujeitos analisados e descobertos pelo estruturalismo e pela hermenêutica, cujas técnicas se mostraram muito poderosas. Em seus estudos, Foucault consegue criticar e, ao mesmo tempo, utilizar esses dois métodos até então hegemônicos e dominantes no pensamento francês da época de um modo extremamente original. Dessa maneira:

Ele tentou evitar a análise estruturalista que eliminava totalmente a noção de sentido, substituindo-a por um modelo formal de comportamento humano que apresenta transformações, governadas por regras, de elementos sem significado; ele tentou evitar o projeto fenomenológico de ligar todo o sentido à atividade de dar sentido de um sujeito autônomo e transcendental; e, finalmente, evitar a tentativa do comentário de ler o sentido implícito das práticas sociais, assim como o desvelar feito pela hermenêutica de um sentido diferente e mais profundo do qual os atores sociais têm uma vaga consciência (Dreyfus \& Rabinow, 1995, p. XX).

Já para Rouanet, atribui-se erroneamente a Foucault o rótulo de pensador pós-moderno. Rouanet exemplifica dizendo que pensadores, tais como Habermas, situam Foucault como pós-modernista, porque além de ter uma postura crítica ele "rejeitaria tanto a modernidade social quanto a cultural" (Rouanet, 1987, p. 219).

De acordo com Rouanet (1987), apesar de em grande parte da obra foucaultiana sua relação com a modernidade se mostrar ambígua, Foucault seria um pensador moderno justamente porque apresenta um espírito iluminista de crítica. No princípio de sua obra havia um espírito moderno frequentemente camuflado por posições antimodernas, mas, ao final, a modernidade aflorou sem qualquer censura.

Rouanet argumenta que Kant inaugurou duas grandes tradições críticas, sendo uma delas concebida como um estudo das condições dentre as quais o conhecimento é possível, ou seja, a analítica da verdade e, outra, referente a uma ontologia do presente, em que se questiona a respeito do que é a nossa atualidade e qual é o campo de experiências possíveis. Dessa maneira, para Foucault, estaríamos atualmente confrontados com a necessidade de se optar por uma dessas tradições críticas e, de acordo com Rouanet, a opção de Foucault foi por uma ontologia do presente, na qual fundou uma reflexão referenciada nessa forma de filosofia que vai desde "Hegel à Escola de Frankfurt, passando por Nietzsche e Max Weber" (Rouanet, 1987, p. 223).

Apesar dessas dificuldades e discordâncias apontadas em situar a obra foucaultiana, esses autores concordam em relação a um aspecto em comum: o da influência de Nietzsche no pensamento de Foucault, seja por meio de sua crítica ao conhecimento e à cultura, seja em relação aos alertas e discussões referentes à hermenêutica, ou até mesmo por sua genealogia.

Merquior (1985) aponta Foucault como um pensador ocidental contemporâneo neonietzcheanista, sendo que sua obra sofreria grande influência do irracionalimo nietzschiano. Já Rouanet indica que, na leitura de Foucault:

Nietzsche não é um Zaratusta epilético espumando verdades iniciáticas, mas o anti-historiador que restaurou os direitos da verdadeira história, a 
wirkliche Historie, desmascarando, com isso, a história metafísica. A genealogia não supõe a intuição profética, mas o saber, a paciência, a erudição, única forma de fazer justiça à história verdadeira - a história das descontinuidades, dos retrocessos, dos ziguezagues, dos recomeços, das lutas intersticiais, dos vazios, dos não acontecimentos (Rouanet, 1987, p. 220).

Oropallo em A presença de Nietzsche no discurso de Foucault salienta que:

Dessa forma, Foucault, em seus escritos, destina várias páginas à interpretação do pensamento de Nietzsche, utilizando-o como ferramenta para seu método de trabalho: seja como modelo, como tarefa filosófica e histórica, como suposto temático, ou ainda através dessa reatualização, inserindo-o no presente para, mediante sua instrumentalização, efetuar um "diagnóstico da atualidade" (Oropallo, 2005, p. 140).

Ao final do século XIX, o pensamento de Nietzsche traz uma crítica contundente não só em relação à possibilidade do conhecimento, mas também ao próprio pensamento e cultura ocidental, ao rejeitar sua configuração ontológica e ao condenar o dogmatismo sempre presente ao longo da história. A crítica ao conhecimento em Nietzsche enfatiza a questão do conceito enquanto representação objetiva e meio adequado de apreender e representar o objeto em nossa experiência no mundo. Nietzsche questiona o conhecimento enquanto possibilidade de delineação e representação do objeto, já que por meio da linguagem, natureza discursiva do conhecimento, não seria possível sua apreensão e representação adequada. A partir disso, Nietzsche ataca a crença epistemológica de que, por meio do conhecimento, se alcançaria a verdade correspondente à realidade, e com isso evidencia uma "condição epistemológica de possibilidade da impossibilidade do conhecimento" (Trapp, 2005, p. 47).

A concepção de conhecimento para Foucault encontra ressonâncias em Nietzsche, tanto no que diz respeito à crítica em relação à crença epistemológica de que por meio do conhecimento se alcançaria a verdade correspondente à realidade, quanto à crítica à configuração ontológica e dogmatismo presentes no pensamento e na cultura ocidental. Enquanto os discursos de inspiração iluminista conceitualizam o conhecimento como razão dirigida a descobrir a verdade inerente à realidade, representando a consciência por meio do referencial da linguagem, Foucault (2000) concebe o conhecimento como discurso composto por práticas que sistematicamente formam objetos dos quais falam, sendo que essas não identificam objetos, mas os constituem e, no ato de fazê-lo, ocultam sua própria invenção.

Para Foucault, o homem moderno foi erigido "no raiar da modernidade, como sujeito da razão transcendental, pela filosofia kantiana, e como sujeito que vive, fala e trabalha, pelas ciências empíricas" (Weinmann, 2006, p. 17). Dessa maneira, a episteme moderna seria inteiramente atravessada por um conceito de sujeito que é universal em sua substância e constituinte da experiência humana em sua diversidade histórica. 0 homem, como um duplo empírico/transcendental, seria então o elemento ordenador de toda produção discursiva com pretensão de cientificidade realizada nos marcos desse sistema de pensamento (Foucault, 2002).

\section{0 individuo em Marx}

De acordo com autores tais como Monteiro (1995), Lopes e Meucci (2005), nos programas de pesquisa das ciências humanas modernas, de um modo geral, o indivíduo aparece como entidade ontológica fundamental, ou seja, cria-se um arcabouço teórico desenvolvido a partir de uma concepção de indivíduo para se explicar o mundo. Segundo esses autores, a obra de Marx se constitui contrariamente a essa tendência, sendo que, em seu sistema, o indivíduo não aparece como centro gravitacional, mas é apenas fenômeno das forças de produção, tendo sua origem derivada do conceito de "classe social".

0 construto teórico de Marx se baseia em verdades ontológicas tais como os conceitos de infraestrutura, superestrutura e de classes sociais. A partir dessa perspectiva, o homem seria forçado a manter contínuo intercâmbio com a natureza de forma a garantir sua sobrevivência, apresentando diferentes modos, forças e relações de produção no decorrer da história. Dessa maneira, Marx chegaria ao conceito de classe social como "segmento econômico engajado no processo produtivo" (Monteiro, 1995, p. 25), ao avaliar as relações sociais que marcaram tais transformações histórico-econômicas. 0 homem, ao 
organizar sua sobrevivência, transformou ao longo da história as condições sociais, políticas e econômicas, desse modo, a economia caracterizaria o terreno próprio do intercâmbio material (infraestrutura) e deveria definir historicamente a organização social (estruturas de classes) e política, como forma de poder e dominação de classe (superestrutura).

A infraestrutura consistiria, assim, nos meios de produção de bens de consumo tais como carros, geladeiras, casas, alimentos, ou até mesmo de bens relativos à prestação de serviços tais como lavanderia $\mathrm{e}$ restaurante. Já a superestrutura, concebida como reflexo da infraestrutura, seria constituída pela ideologia, formas de cultura, pela política, pelo judiciário e, principalmente, pelo Estado (Lopes \& Meucci, 2005).

Esses conceitos, infraestrutura, superestrutura e classes sociais, formariam o axioma ontológico fundamental da obra de Marx, pois em sua estrutura lógica de explicação não se poderia negá-lo em hipótese alguma, já que seria o principal responsável pelas explicações e elaborações a respeito da realidade e das demais proposições do próprio sistema. Dessa maneira, conforme relata Lopes e Meucci (2005, p. 98):

Todo fenômeno social deve ser explicado pelas estruturas econômicas e pelo reflexo destas nos meios de produção (propriedades, matéria-prima, maquinário, classes produtivas etc.). Com isso, todos os esforços para solucionar os problemas devem ter em vista os meios de produção, e não diretamente os indivíduos. A partir desse axioma de Marx, podemos derivar um segundo. Outra verdade ontológica: as classes sociais. [...] a infraestrutura gera a divisão do trabalho, que, por sua vez, gera as classes sociais que, finalmente, constitui o indivíduo.

Monteiro (1995) discute a respeito dessa questão da subjetividade, pouco explorada na obra de Marx. Segundo o autor, há algumas aporias (contradições conceituais) encontradas no marxismo, sendo que essas apresentam alguns determinismos encontrados em seu sistema teórico, como o econômico, histórico e o sociológico. Sendo assim, se por um lado a sociedade está estruturada em classes segundo a anatomia econômica e o modo de produção historicamente situado, por outro a própria tendência histórica seria a de superação das classes graças à ação da classe proletária, para que, "na futura sociedade sem classes, o indivíduo resolva suas contradições tanto em relação à sociedade quanto em relação à história" (Monteiro, 1995, p. 27). 0 indivíduo, nesse caso, não se apresenta como entidade ontológica fundamental na qual se moldará o construto hipotético de Marx, mas, contrariamente a isso, só aparecerá como um possível resultado.

\section{Os neomarxistas}

Para Monteiro (1995), é preciso que se ressaltem os pontos importantes encontrados no pensamento de Marx, mas também que se critique e situe as concepções obsoletas, ultrapassadas. Monteiro (1995) enfatiza, ainda, que somente a partir das últimas décadas o marxismo passou a superar alguns preconceitos e criar um diálogo com outros autores e concepções não marxistas, além de se colocar pela primeira vez como seu próprio objeto de crítica. A partir daí, várias correntes e concepções neomarxistas se propuseram efetivamente a formular críticas a alguns pontos do marxismo e a resgatar concepções importantes, acrescentando assim discussões a respeito da subjetividade. Essas vertentes neomarxistas fazem um resgate do individualismo ético (realização do indivíduo por meio da liberdade), do universalismo ético (democracia e igualdade) e da reflexão racional (emancipação e liberdade subjetiva), indicando esses caminhos para a superação da ideologia e da alienação e para novos conceitos de subjetividade, sem perder de vista a crítica aos fatores objetivos (Monteiro, 1995).

Monteiro (1995) ainda destaca as contribuições de outros pensadores não marxistas como, por exemplo, Foucault, tanto em relação à discussão a respeito das novas abordagens para a questão da subjetividade, formulando uma crítica implícita às psicologias tradicionais, quanto ao diálogo entre suas concepções teóricas junto às proposições marxistas ou neomarxistas.

Foucault traz uma contribuição a partir de sua perspectiva no que diz respeito à relação saber/poder, contrariamente à concepção marxista, em que o poder seria concentrado em determinados segmentos da sociedade, agindo, de certa forma, de maneira opressora. Para Foucault (2000), tais diagramas de poder não estariam apenas concentrados no Estado ou governo, mas nas relações cotidianas, 
pulverizados em todas as formações discursivas. Por exemplo, o poder não seria uma posse que se encontra na figura do opressor, mas está tanto no opressor quanto no que se deixa oprimir, simultaneamente. 0 poder, nessa perspectiva, seria não apenas opressivo, mas criativo e constitutivo.

Em suas pesquisas, Foucault (2000) revela que as relações de poder não estariam subordinadas a algum segmento da vida social como, por exemplo, o econômico, mas que as técnicas disciplinares preexistiriam ao sistema capitalista. Dessa forma, conforme Foucault (2000), o capital funcionaria como uma rede complexa, não apenas agindo como uma iguaria produtora de força de trabalho, mas também na produção de processos de subjetivação, produzindo história subjetiva, modos de ser, sentir, pensar e amar.

Monteiro (1995) discute um possível caminho para o prosseguimento da crítica sobre as teorias da subjetividade, o qual deveria ser traçado a partir da tentativa de responder às questões epistemológico-metodológicas e ético-ontológicas, recolocando seus problemas conceituais imbricados a fim de se distinguirem as demonstrações científicas ainda questionáveis, de certa maneira, do plano das convicções metafísicas, eticamente necessárias. Nesse sentido, o que interessaria seria uma crítica que transitasse entre a ciência e a filosofia, já que as questões éticas ultrapassariam os limites da ciência, perpassando também, dessa maneira, a ordem metafísica. Segundo Monteiro (1995), seria aí que o socialismo tomado como valor conceitual permaneceria como um horizonte utópico racional aberto, no qual se defenderia um compromisso teórico e prático voltado à crítica social a partir de bases neomarxistas que possam manter tal horizonte humanista.

Em alusão aos apontamentos de Monteiro (1995), Foucault, em sua Estética da existência, na qual enfatiza o estudo da subjetividade e das práticas de si, reflete a respeito de o que podemos ser e do como nos produzimos como sujeitos. Assim, Foucault aponta para a possibilidade de se criar, de maneira autônoma, a forma desejada de existência. Dessa maneira, os valores éticos que, segundo Foucault, seriam construídos baseando-se no conhecimento científico, poderiam ser superados por meio de uma ética que ficaria responsável por essa construção diária do sujeito, de forma a ultrapassar o dito científico. Apesar de Foucault não propor uma crítica social colocada sob um pano de fundo neomarxista como horizonte utópico, conforme defendido por
Monteiro (1995), ele enfatiza, de certa forma, essa problemática de que as questões éticas estariam para além dos limites da ciência e que seriam, por fim, fundamentais para que o homem realize o trabalho sobre si, fabricando a si mesmo e constituindo suas regras de convívio social (Ortega, 1999).

\section{Considerações finais}

A questão da díade subjetividade/objetividade, debatida e explorada pelas mais diversas tendências teórico-metodológicas, apresenta tanto ressonâncias quanto discordâncias no que diz respeito às possibilidades de desenvolvimento de uma ciência ou de um sistema filosófico e, consequentemente, em relação à possibilidade de se construir um conhecimento sobre o mundo. A discussão a respeito desses modelos teóricos e de suas respectivas metodologias, tal como realizado no decorrer deste trabalho a partir de Foucault e Marx, mostra-se relevante não apenas devido às soluções e contribuições propostas por cada sistema de pensamento, mas também por essas proposições servirem como elementos de precaução e alerta contra tendências e posturas ingênuas ou fundamentalistas que ignorem e desrespeitem as possibilidades e contrapontos existentes nas mais diversas correntes de pensamento, fechando-se, dessa forma, ao diálogo e a possíveis contribuições oferecidas por concepções de outros autores, desenvolvidas a partir de outros referenciais. Nesse sentido, o importante é que se possibilite uma interlocução e crítica que transite entre os mais diversos aportes teóricos e áreas, a fim de se discutir eticamente os limites referentes aos mais variados construtos hipotéticos e suas respectivas tendências metodológicas, defendendo-se, assim, um compromisso teórico e prático implicado com a crítica social.

\section{Referências}

Dreyfus, H. C., \& Rabinow, P. (1995). Michel Foucault:Uma trajetória filosófica - Para além do estruturalismo e da hermenêutica. Rio de Janeiro: Forense Universitária.

Foucault, M. (2002). As palavras e as coisas: Uma arqueologia das ciências humanas. São Paulo: Martins Fontes. (Obra original publicada em 1966). 
Foucault, M. (2000). Microfísica do poder. Rio de Janeiro: Graal.

Lopes, F. T. P., \& Meucci, A. (2005). Marxismo e freudismo: Dessemelhanças e semelhanças epistemológicas. Natal: Princípios.

Merquior, J. G. (1985). Michel Foucault ou o niilismo de cátedra. Rio de Janeiro: Nova Fronteira.

Monteiro, L. G. M. (1995). Objetividade x Subjetividade: da crítica à psicologia à psicologia crítica. In S. T. Lane \& B. B. Sawaia (Org.) Novas veredas da psicologia social. São Paulo: Brasiliense.
Oropallo, M. C. (2005). A presença de Nietzsche no discurso de Foucault. Tese de mestrado, Universidade São Judas Tadeu, São Paulo.

Ortega, F. (1999). Amizade e estética da existência em Foucault. Rio de Janeiro: Graal.

Rouanet, S. P. (1987). As razões do iluminismo. São Paulo: Companhia das Letras.

Trapp, R. V. (2005). Nietzsche: Do problema no conhecimento para o conhecimento como problema. Analecta, 6(1), 45-62.

Weinmann, A. O. (2006). Dispositivo: um solo para a subjetivação. Psicologia \& Sociedade, 18(3), 16-22. 